\title{
Adjuvant radiotherapy and chemotherapy in breast cancer: 30 year follow-up of survival
}

\author{
Colin S McArdle ${ }^{1}$, Donald C McMillan", Nicola Greenlaw², David S Morrison²*
}

\begin{abstract}
Background: The long term outcome (more than 15 years) of adjuvant treatment in patients with primary operable breast cancer has rarely been examined.

Methods: A randomised clinical trial of radiotherapy, chemotherapy (28 day cycles of cyclophosphamide, methotrexate and 5 -fluorouracil) or both on women with primary operable breast cancer $(n=322)$ was followedup for a median of 27 years.

Results: 260 (81\%) patients died, 204 (78\%) from breast cancer. Cancer specific survival (SE) at 10 years, 20 years and 30 years was 41 (3)\%, 34 (3)\% and 33 (3)\% respectively. Presence of more than 3 involved lymph nodes increased cancer-specific mortality ( $\mathrm{HR} 1.88,95 \% \mathrm{Cl} 1.34-2.63)$ after adjustment for age, socio-economic deprivation and adjuvant treatment. Both age (HR 1.63,95\% Cl 1.19-2.22) and involved lymph nodes (HR 1.59, 95\% Cl 1.17-2.14) were significant predictors of all-cause mortality after adjustment for other factors. There was no significant difference in all-cause or cancer-specific survival between patients in each of the 3 treatment arms.

Conclusions: The present study highlights the long term impact of node positive disease but does not indicate that any regimen was associated with significantly better long-term survival.
\end{abstract}

\section{Background}

Breast cancer is the commonest malignancy in females and is a major cause of morbidity and mortality in the Western World[1]. Prior to the introduction of chemotherapy the mainstay of treatment was based on surgery and radiotherapy. A series of clinical trials started in the mid $1970 \mathrm{~s}$, with approximately 5 years' followup, established the role of chemotherapy as an adjuvant treatment for primary operable breast cancer[2-5].

In contrast, the long term outcome of such adjuvant treatment in these patients is less clear. Recently, Bonadonna and co-workers[6] reported that, after follow-up of 30 years, adjuvant cyclophosphamide, methotrexate, and fluorouracil (CMF) was associated with a persistent reduction in overall mortality of approximately $20 \%$ compared with surgery alone. However, to our knowledge, there have been no reports that compare long term survival in patients receiving CMF with two of the commonest alternative regimens for primary operable

\footnotetext{
* Correspondence: david.morrison@nhs.net

${ }^{2}$ West of Scotland Cancer Surveillance Unit, Section of Public Health and Health Policy, Faculty of Medicine, University of Glasgow, Glasgow, UK, G12
} $8 R Z$

C 2010 McArdle et al; licensee BioMed Central Ltd. This is an Open Access article distributed under the terms of the Creative Commons Attribution License (http://creativecommons.org/licenses/by/2.0), which permits unrestricted use, distribution, and reproduction in any medium, provided the original work is properly cited. breast cancer, CMF combined with radiotherapy and radiotherapy alone[3].

The aim the present study was therefore to establish long term outcome in women receiving adjuvant radiotherapy and chemotherapy as part of a randomised trial.

\section{Methods}

The study design has been previously described[3]. Briefly, between June 1976 and December 1982 women aged 70 years or less admitted to three teaching hospitals, with operable breast cancer and with no evidence of metastatic disease, were entered into the study. Women with histological involvement of the axillary nodes were randomized to receive either: conventional postoperative radiotherapy, chemotherapy alone or radiotherapy followed by chemotherapy. The chemotherapy regimen was based on that described by Bonadonna - consecutive 28 day cycles of cyclophosphamide, methotrexate and 5-fluorouracil[2].

Information on date and cause of death was obtained through Scottish Cancer Registry patient-based linkage with the General Register Office for Scotland $(\mathrm{GRO}(\mathrm{S}))$ death records. Deaths up to the end of $30^{\text {th }}$ September

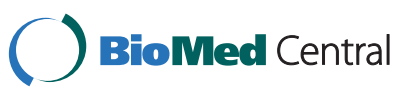


2007 have been included in the analysis, providing a median length of follow-up of 27 years (minimum 25 years, maximum 31 years). Cancer-specific survival was calculated using all deaths in which the principal cause of death was recorded as breast cancer (International Classification of Diseases, Revision 9, 174 and 199; ICD10 C50). Socio-economic deprivation was inferred for each patient using the DEPCAT score[7] associated with their postcode of residence. The DEPCAT is a validated 7 -category score that ranks all postcode areas from 1 (most affluent) to 7 (most deprived) using four Census variables shown best to correlate with health outcomes: car ownership; overcrowding; proportion of population in occupational Social Classes IV and V; and male unemployment. We further grouped DEPCATs into 3 conventional classes: DEPCATs 1 and 2 (affluent); 3 to 5 (intermediate); and 6 and 7 (deprived).

\section{Statistics}

Cumulative survival after mastectomy was estimated using the Kaplan-Meier method and the logrank used to test for independence between treatment groups. The grouping of variables was carried out using standard thresholds. Life tables showing cancer-specific survival and associated standard errors were calculated using SPSS version 15 software. Univariate and multivariate survival analysis and calculation of hazard ratios (HRs) were carried out using Cox's proportional-hazards model. Analysis was carried out using STATA version 10 statistical software. Multivariate analyses were stratified by oestrogen receptor status in order to satisfy the proportionality assumption, which was tested using the calculated Schoenfeld residuals and the scaled Schoenfeld residuals [8]. These residuals are used to test the null hypothesis that the log hazard-ratio function is constant over time, that is, that the ratio of hazards between different groups (for example, between patients aged 50 or less and over-50) is constant over time.

\section{Results}

Three hundred and twenty-two patients were included in the study. One hundred and three patients were allocated to receive radiotherapy alone, 111 sequential radiotherapy and chemotherapy and 108 chemotherapy alone. The incidence of unfavourable prognostic features, such as age, deprivation, tumour size, involved lymph nodes, and oestrogen receptor status, was similar between the groups.

After 30 years' follow-up 260 (81\%) died; of these 204 (78\%) died of breast cancer. Cancer specific survival (SE) at 10 years, 20 years and 30 years was 41 (3)\%, 34 (3)\% and 33 (3)\% respectively. All-cause survival (SE) at 10 years, 20 years and 30 years was 37 (3)\%, $23(2) \%$ and 19 (2)\% respectively. There was a trend towards improved cancer-specific survival in the sequential radiotherapy and chemotherapy arm but no overall difference in either breast cancer-specific (Figure 1, logrank $\mathrm{p}=0.090)$ or all-cause survival $(\mathrm{p}=0.154)$ between groups.

The relationships between clinicopathological features and treatment and both cancer-specific and overall survival at 30 years are shown in Table 1. Age over 50 years, and more than 3 involved lymph nodes, were associated with significantly poorer cancer-specific and all-cause survival. Formally defined post-menopausal status was associated with poorer overall survival but not with cancer-specific survival.

The relationships between clinicopathological features, treatment and both cancer-specific and overall survival were explored by multivariate proportional hazards analyses and results shown in Table 2 . Increasing age $(\mathrm{p}=0.018)$ and involved numbers of lymph nodes $(\mathrm{p}<0.001)$ were associated with poorer cancer specific survival in univariate analysis. On multivariate analysis, shown in Table 2, only involved lymph nodes (HR 1.88, 95\% CI 1.34-2.63) remained significant determinants of cancer-specific survival. Both age (HR 1.63, 95\% CI 1.19-2.22) and involved lymph nodes (HR 1.59, 95\% CI 1.17-2.14) were significant predictors of all-cause mortality after adjustment for other factors. There was no significant difference in all-cause or cancer-specific survival between patients in each of the 3 treatment arms. There were no significant interactions between survival from each of the 3 treatment modalities and age, deprivation or number of involved lymph nodes.

\section{Discussion}

In the present study there was an approximate $80 \%$ reduction in 30 year cancer-specific survival in those patients with 4 or more involved lymph nodes. In contrast, there was no significant impact of treatment modality on long term cancer survival. Therefore, the present study confirms the long term impact of node positive disease but does not indicate that any regimen was associated with significantly better long-term survival.

The results of the present study are therefore consistent with our previous report of the 5 year results of this randomised trial comparing adjuvant radiotherapy, radiotherapy and chemotherapy and chemotherapy alone in women with primary operable breast cancer[3]. The main findings then were that the combination of radiotherapy and chemotherapy was associated with reduced recurrence and a trend towards increased cancer-specific survival; and that disease-related survival was mainly dependent on the number of positive nodes. The present results are also consistent with other reports which indicate that while radiotherapy reduces 


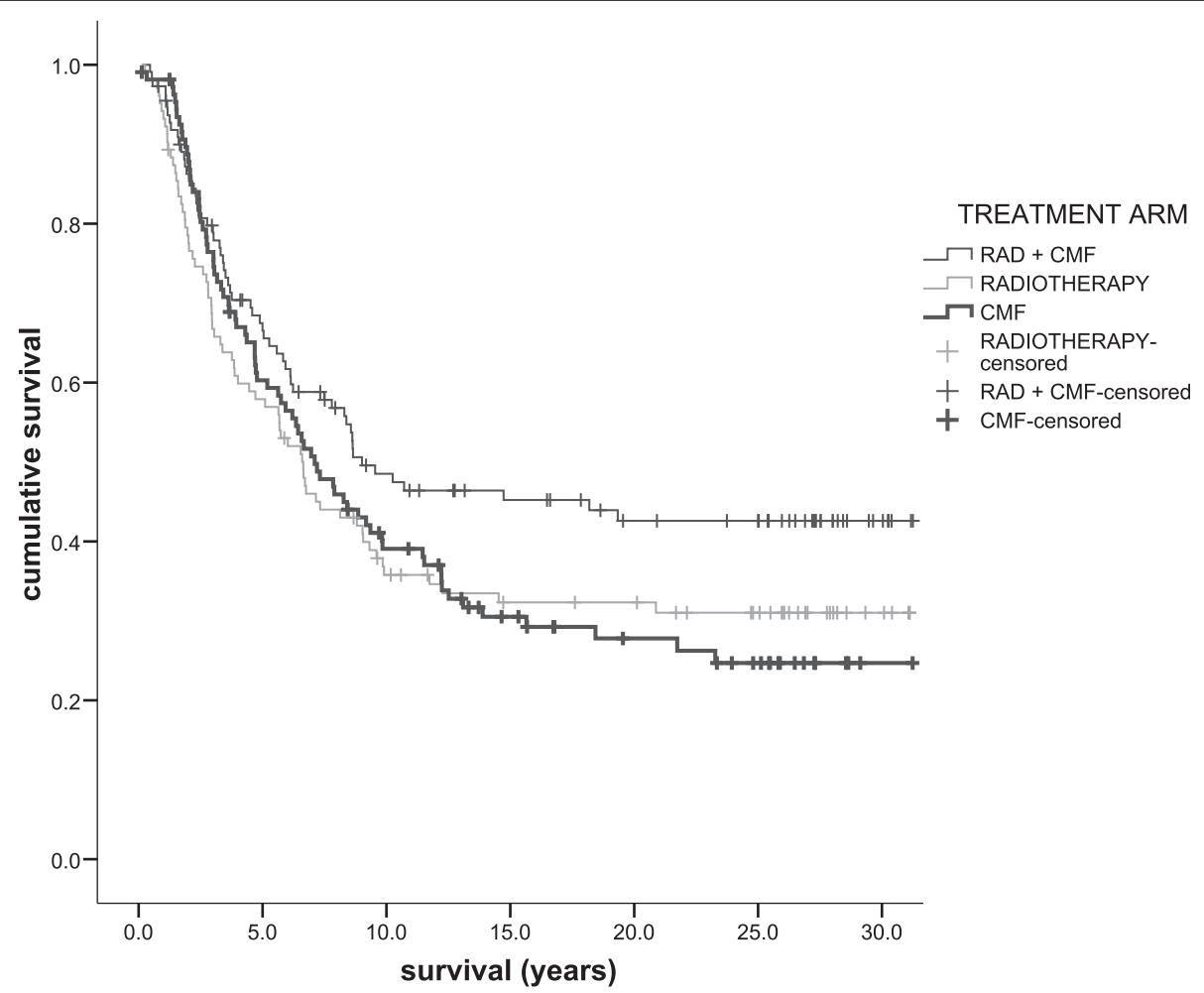

Figure 1 The relationship between treatment (radiotherapy and chemotherapy/radiotherapy/chemotherapy from top to bottom) and cancer specific survival in patients with primary operable breast cancer with 30 year follow-up.

Table 1 30-year cancer specific and overall cumulative survival for patients undergoing adjuvant radiotherapy and chemotherapy with primary operable breast cancer, $n=322$

\begin{tabular}{|c|c|c|c|c|}
\hline & $\begin{array}{l}\text { Cancer-specific } \\
\text { survival }\end{array}$ & p-value & $\begin{array}{l}\text { Overall } \\
\text { survival }\end{array}$ & p-value \\
\hline \multicolumn{5}{|l|}{ Age } \\
\hline$\leq 50$ years & $40(5)$ & 0.023 & $31(2)$ & 0.001 \\
\hline$>50$ years & $28(3)$ & & $12(2)$ & \\
\hline \multicolumn{5}{|l|}{ Socio-economic circumstances } \\
\hline Affluent (DEPCATs 1-2) & $41(6)$ & & $24(5)$ & \\
\hline Intermediate (DEPCATs 3-5) & $33(4)$ & 0.657 & $19(3)$ & 0.784 \\
\hline Deprived (DEPCATs 6-7) & $27(5)$ & & $14(4)$ & \\
\hline \multicolumn{5}{|l|}{ Menopausal status } \\
\hline Pre & $39(4)$ & 0.071 & $30(4)$ & 0.002 \\
\hline Post & $29(4)$ & & $12(2)$ & \\
\hline \multicolumn{5}{|l|}{ Involved lymph node } \\
\hline$\leq 3$ & $38(4)$ & $<0.001$ & $21(3)$ & $<0.001$ \\
\hline$>3$ & $23(4)$ & & $14(3)$ & \\
\hline \multicolumn{5}{|l|}{ Hormonal-receptor status } \\
\hline ER+ & $33(5)$ & 0.052 & $17(4)$ & 0.055 \\
\hline
\end{tabular}

the risk of loco-regional recurrences[9,10], it has no effect on mortality at 20 years (although Rutqvist also reported that chemotherapy was associated with longer recurrence-free survival among premenopausal women only)[10]. A meta-analysis suggests that the modest benefits of radiotherapy on breast cancer specific mortality are offset by increased mortality from other causes[11]. While Fisher and others' trial[12] - which began in the same year as the present study - found that the addition of radiotherapy to segmental mastectomy conferred a significant survival advantage, it may be that longerterm follow-up would also have shown increased 
Table 2 Multivariate hazards of breast cancer-specific and all cause mortality at 30 years for 322 patients undergoing adjuvant radiotherapy and chemotherapy with primary operable breast cancer, stratified by oestrogen receptor status

\begin{tabular}{|c|c|c|c|c|c|}
\hline & $\begin{array}{l}\text { Patients } \\
(\mathrm{n}=322)\end{array}$ & $\begin{array}{l}\text { Cancer-specific } \\
\text { Hazard ratio } \\
(95 \% \mathrm{Cl})\end{array}$ & $\begin{array}{l}\text { survival } \\
P \text {-value }\end{array}$ & $\begin{array}{l}\text { Overall } \\
\text { Hazard ratio } \\
(95 \% \mathrm{Cl})\end{array}$ & $\begin{array}{l}\text { survival } \\
P \text {-value }\end{array}$ \\
\hline Age (>50 years) & & $1.34(0.95-1.89)$ & 0.097 & $1.63(1.19-2.22)$ & 0.002 \\
\hline Deprivation (DEPCAT) & & & 0.226 & & 0.322 \\
\hline $1-2$ & & 1.00 & & 1.00 & \\
\hline $3-5$ & & $1.04(0.68-1.60)$ & 0.845 & $0.94(0.65-1.36)$ & 0.740 \\
\hline $6-7$ & & $1.39(0.90-2.14)$ & 0.144 & $1.21(0.82-1.77)$ & 0.332 \\
\hline \multicolumn{6}{|l|}{ Involved lymph nodes } \\
\hline 1,2 or 3 & & 1.00 & & 1.00 & \\
\hline$\geq 4$ & & $1.88(1.34-2.63)$ & $<0.001$ & $1.59(1.17-2.14)$ & 0.003 \\
\hline Treatment & & & 0.220 & & 0.309 \\
\hline Radiotherapy & & $1.24(0.81-1.90)$ & 0.324 & $1.02(0.70-1.48)$ & 0.921 \\
\hline Radiotherapy + CMF & & 1.00 & 1.00 & 1.00 & \\
\hline CMF & & $1.43(0.96-2.13)$ & 0.082 & $1.28(0.90-1.81)$ & 0.169 \\
\hline
\end{tabular}

CMF, cyclophosphamide, methotrexate and 5-fluorouracil.

mortality from others causes. It seems unlikely that differences in surgical interventions between treatment arms - a choice of breast conserving surgery of mastectomy - would have influenced long-term survival[13-15]. A systematic review of chemotherapy trials for breast cancer found that adjuvant polychemotherapy reduced mortality in postmenopausal women by $2 \%$ and $6 \%$ in node negative and node positive women, respectively [16]. However, the observed effect may have been be due to the additional benefits of tamoxifen on long-term survival[17] and the drug was not available in the United Kingdom at the start of the present study.

The present study has a number of limitations, principally that we did not have data on tumour grade with which we might have been able to calculate the Nottingham Prognostic Index[18] nor did we have more detailed data on doses and compliance with each treatment modality. Death records may be susceptible to coding errors and misclassification of the cause of death might have either increased or decreased the true causespecific mortality. The lack of statistically significant differences in survival between treatment arms may be due to insufficient numbers of patients; it may reflect a true absence of effect; or unidentified confounding factors may have obscured a true difference. Nevertheless, the major strength of the present study is the duration of follow up, which, with the exception of the study by Bonadonna[2], is to our knowledge the longest reported.

\section{Conclusions}

Although there have been advances in the surgical, radiological and chemotherapeutic treatment of primary operable breast cancer over the past 30 years the present results highlight the long lasting detrimental effect of node positive disease. Our analysis describes the impact of the first adjuvant regimens but does not indicate that any regimen was associated with significantly better long-term survival.

\section{Acknowledgements}

The authors would like to thank the clinicians who participated in the study in particular David C Smith, Michael Soukop and the late David Hole.

\section{Author details}

${ }^{1}$ University Department of Surgery, Faculty of Medicine, University of Glasgow, Royal Infirmary, Glasgow, UK, G31 2ER. ${ }^{2}$ West of Scotland Cancer Surveillance Unit, Section of Public Health and Health Policy, Faculty of Medicine, University of Glasgow, Glasgow, UK, G12 8RZ.

\section{Authors' contributions}

CSM designed the study and gathered original clinical data; DSM obtained and linked deaths records; DCM, DSM and NG designed this follow-up study, conducted statistical analyses, and drafted the manuscript; all authors saw and approved the final version of the manuscript.

\section{Competing interests}

The authors declare that they have no competing interests.

Received: 5 January 2010 Accepted: 30 July 2010

Published: 30 July 2010

\section{References}

1. Parkin DM, Bray F, Ferlay J, Pisani P: Global cancer statistics, 2002. CA Cancer J Clin 2005, 55:74-108.

2. Bonadonna $G$, Brusamolino $E$, Valagussa $P$, Rossi $A$, Brugnatelli L, Brambilla C, De Lena M, Tancini G, Bajetta E, Musumeci R, Veronesi U: Combination chemotherapy as an adjuvant treatment in operable breast cancer. N Engl J Med 1976, 294(8):405-10.

3. McArdle CS, Crawford D, Dykes EH, Calman KC, Hole D, Russell AR, Smith DC: Adjuvant radiotherapy and chemotherapy in breast cancer. $\mathrm{Br}$ J Surg 1986, 73:264-6. 
4. Early Breast Cancer Trialists' Collaborative Group (EBCTCG): Effects of chemotherapy and hormonal therapy for early breast cancer on recurrence and 15-year survival: an overview of the randomised trials. Lancet 2005, 365(9472):1687-717.

5. Newman LA, Singletary SE: Overview of adjuvant systemic therapy in early stage breast cancer. Surg Clin North Am 2007, 87:499-509.

6. Bonadonna G, Moliterni A, Zambetti M, Daidone MG, Pilotti S, Gianni L, Valagussa P: 30 years' follow up of randomised studies of adjuvant CMF in operable breast cancer: cohort study. BMJ 2005, 330(7485):217.

7. McLoone P: Carstairs scores for Scottish postcode sectors from the 2001 Census. Glasgow: MRC Social \& Public Health Sciences Unit 2004

8. Schoenfeld D: Partial residuals for the proportional hazards regression model. Biometrika 1982, 69:239-41.

9. Killander F, Anderson H, Rydén S, Möller T, Hafström LO, Malmström P: Efficient reduction of loco-regional recurrences but no effect on mortality twenty years after postmastectomy radiation in premenopausal women with stage II breast cancer - a randomized trial from the South Sweden Breast Cancer Group. Breast 2009, 18(5):309-15.

10. Rutqvist LE, Johansson H: Long-term follow-up of the Stockholm randomized trials of postoperative radiation therapy versus adjuvant chemotherapy among 'high risk' pre- and postmenopausal breast cancer patients. Acta Oncol 2006, 45(5):517-27.

11. Early Breast Cancer Trialists' Collaborative Group: Favourable and unfavourable effects on long-term survival of radiotherapy for early breast cancer: an overview of the randomised trials. Lancet 2000, 355(9217):1757-70

12. Fisher B, Bauer M, Margolese R, Poisson R, Pilch $Y$, Redmond C, Fisher E, Wolmark N, Deutsch M, Montague E, Saffer E, Wickerham L, Lerner H, Glass A, Shibata H, Deckers P, Ketcham A, Oishi R, Russell I: Five-year results of a randomized clinical trial comparing total mastectomy and segmental mastectomy with or without radiation in the treatment of breast cancer. NEJM 1985, 312(11):665-673.

13. Blichert-Toft M, Nielsen M, Düring M, Møller S, Rank F, Overgaard M Mouridsen $\mathrm{HT}$ : Long-term results of breast conserving surgery vs. mastectomy for early stage invasive breast cancer: 20-year follow-up of the Danish randomized DBCG-82TM protocol. Acta Oncol 2008, 47(4):672-81.

14. Veronesi U, Cascinelli N, Mariani L, Greco M, Saccozzi R, Luini A, Aguilar M, Marubini E: Twenty-year follow-up of a randomized study comparing breast-conserving surgery with radical mastectomy for early breast cancer. NEJM 2002, 347(16):1227-32.

15. van Dongen JA, Voogd AC, Fentiman IS, Legrand C, Sylvester RJ, Tong D, van der Schueren E, Helle PA, van Zijl K, Bartelink H: Long-term results of a randomized trial comparing breast-conserving therapy with mastectomy: European Organization for Research and Treatment of Cancer 10801 trial. J Natl Cancer Inst 2000, 92(14):1143-50.

16. Bergh J, Jönsson PE, Glimelius B, Nygren P, SBU-group: Swedish Council of Technology Assessment in Health Care. A systematic overview of chemotherapy effects in breast cancer. Acta Oncol 2001, 40(2-3):253-81.

17. Vorgias G, Koukouras D, Tzoracoeleftherakis E, Paleogianni V, Androulakis J: Adjuvant tamoxifen versus tamoxifen plus CMF in the treatment of early breast cancer in Greece. Fifteen-year results of a randomised prospective trial and the potential risks of the antioestrogen. Anticancer Res 2000, 20(5C):3849-54

18. Galea MH, Blamey RW, Elston CE, Ellis IO: The Nottingham Prognostic Index in primary breast cancer. Breast Cancer Res Treat 1992, 22(3):207-19.

\section{Pre-publication history}

The pre-publication history for this paper can be accessed here: http://www.biomedcentral.com/1471-2407/10/398/prepub

doi:10.1186/1471-2407-10-398

Cite this article as: McArdle et al.: Adjuvant radiotherapy and chemotherapy in breast cancer: 30 year follow-up of survival. BMC Cancer 2010 10:398.

\section{Submit your next manuscript to BioMed Central and take full advantage of:}

- Convenient online submission

- Thorough peer review

- No space constraints or color figure charges

- Immediate publication on acceptance

- Inclusion in PubMed, CAS, Scopus and Google Scholar

- Research which is freely available for redistribution

Submit your manuscript at www.biomedcentral.com/submit
Biomed Central 